Anais do Encontro Paraibano de Biblioteca Escolar

\title{
RECURSOS AUXILIARES E CRIATIVOS PARA CONTAÇÃO DE HISTÓRIAS NA BIBLIOTECA ESCOLAR
}

\author{
Ana Cleide Patrício de Souza \\ Bibliotecária \\ ana2004cleide@hotmail.com
}

\section{Resumo}

\begin{abstract}
Nos últimos anos a contação de histórias ganhou destaque como instrumento positivo de ação educativa na Biblioteca Escolar somando no processo da aprendizagem. Atraves de uma pesquisa bibliográfica e de algumas vivências apontamos recursos criativos para dinamizar a contação de histórias contribuindo para uma educação leitora, lúdica e divertida, no presente trabalho realizado com a intenção de difundi recursos auxiliares e criativos. Conclui-se que a valorização da contação de histórias contribui para um desenvolvimento da criança e o gosto pela leitura, a contação de história mostrou-se uma saída para promover, estimular e atrair para biblioteca através do encantamento das palavras.
\end{abstract}

Palavras-chave: Leitura. Estímulo. Dinâmicas.

\section{INTRODUÇÃO}

A importância da leitura é de extrema valorização em nossas vidas, são diversos os benefícios que podemos destacar como: ampliar e integrar conhecimentos, enriquecer nosso vocabulário, facilita a comunicação e nos faz refletir sobre nossos atos.

O mesmo acontece quando ouvimos uma história, elas um papel fundamental na formação da criança. Além de ser um fator de desenvolvimento da linguagem e consequentemente para despertá-lo para a leitura. A contação de histórias é arte.

Busatto (2006, p.74) a intenção de inserir história no contexto escolar é de propiciar, cultura, conhecimento, princípios, valores, educação, ética, além de contribuir para uma boa construção de relacionamentos afetivos saudáveis, como: carinho, afeto bons tratos, cuidados pessoais, reeducação alimentar, autoestima.

Conforme Paulo Freire (1992), a leitura do mundo precede a leitura da palavra. E a leitura desta implica sempre a continuidade da primeira. O prazer de ler é antecipado pelo prazer da escrita e da observação e evolui para uma atitude de curiosidade leitora diante da vida.

O presente trabalho trata-se de uma pesquisa bibliográfica, realizada com o intuito de contribuir e difundir recursos auxiliares utilizados na contação de histórias, servindo como estratégia de estímulo e incentivo a leitura.

\section{ESPAÇO PARA A CONTAÇÃO DE HISTÓRIAS}

A contação de histórias além de ser uma atividade divertida que movimenta qualquer biblioteca é sempre um momento de atração e mantém a tradição da cultura perpetuando as histórias por várias gerações.

Podemos dizer que a contação de historias é um ritual de encantamento entre os ouvintes e aquele que contará a história.

Agrada a todos sem fazer distinção de idade, classe social ou circunstância de vida. A história narrada, por escrito ou oralmente, nos permite também aquisições em diversos níveis. Isto é: contar histórias para as crianças permite conquistas, no mínimo, nos planos psicológico, pedagógico, histórico, social, cultural e estético. (SISTO, p.01).

Busque um lugar aconchegante antes de contar a história, fique posicionada onde todos possam visualiza-la e motive-os para despertar curiosidades, conheça história é primordial planejamento, verificando a quantidade de crianças, o tempo disponível, por vezes a contação é realizada no pátio, auditório ou 
jardim da escola, debaixo da árvore, na biblioteca ou outro lugar.

O espaço físico é importante, se for necessário possível com alguma decoração, aromas, criando uma atmosfera para que a criança se identifique e crie uma memória afetiva. Antes de começar qualquer história converse com os participantes, fale quem é você e forma espontânea para que as crianças conheçam o bibliotecário, aproveite $\mathrm{o}$ momento para falar sobre o livro e a importância de todos cuidarem dele. Envolvaos.

Faça uma introdução rápida do enredo e fale sobre a opção de contar aquela história especificamente. Antecipe possíveis dúvidas. Informe que é importante o grupo se manter em silêncio para ouvir a contação. As perguntas devem ser respondidas somente no término da atividade (REVISTA NOVA ESCOLA, 2012).

Os bibliotecários, professores, mediares e contadores de historias são os principais agentes para promover a prática no cotidiano escolar. Apresente o livro, citando o nome do autor e do ilustrador, essa técnica serve para que a criança valorize o trabalho dos profissionais envolvidos na confecção da obra.

Alguns cuidados devem ser tomados, preserve os detalhes. Cuide da postura corporal para que os movimentos enriqueçam a contação. Fique atento à impostação de voz, respeitando o desenrolar da trama e as características dos personagens. (REVISTA NOVA ESCOLA, 2012). Mostre alegria e entusiasmo, deixe seu corpo falar, use aromas, texturas e faça com que a criança viaje na leitura.

A duração da história deve esta de acordo com a faixa etária do publico ouvinte, onde para os menores fique entre 5 e 10 minutos, e para os maiores, de 15 a 20 minutos sendo, portanto o tempo é flexível para que não se torne algo chato.

Buscar temas que possam auxiliar na solução de algum problema com: má alimentação, obesidade e outros temas; conforme o público e pode repetir a história se for desejo das crianças, ao final interaja questione, reinvente a história. Deixem com que eles participem.

\section{RECURSOS PARA CONTAÇÃO DE HISTÓRIAS, VIVÊNCIAS E DINÂMICAS}

O bibliotecário-contador de histórias, pode e deve ser criativo e ousado, buscando recursos que colaborem para aguçar a imaginação e a fantasia dos ouvintes. Mesmo que não tenha técnica, desenvolva e aprimore cada um encontra sua forma de contar e encantar. E não existe nenhum problema em recontar ou repetir.

Inúmeros recursos podem auxiliar na hora da contação de histórias e são comumente utilizados ao longo do tempo por bibliotecários-contadores, mediadores, professores e alguns pais.

Há uma diversidade de recursos possíveis e outros que podem ser criados conforme a criatividade e a inovação daquele que contará a história. Alguns são bem conhecidos e tem vários disponíveis no mercado e também podem ser confeccionados são: livros de tecidos ou feltros; cineminhas, DVD, Apresentações em slides (PowerPoint pode ser usado em casos excepcionais, quando os ouvintes tiver um grande quantitativo), flanelógrafos, tapetes, teatro de sobras, luvas, fantoches (dedoches, palitoches e similares), mascaras, Avental, Caixas, maletas de histórias, baú de histórias, tecidos, dobraduras ou outro objeto que possa ganhar vida.

Esses recursos auxiliam na apresentação de histórias, que, além de serem ouvidas, passam a ser assistidas, manuseadas, cantadas utilizando-se de outras linguagens como: a música, a mímica, a dança, as artes plásticas' e 'tudo é bem vindo quando desperta o sabor de um passeio com o qual se sonhou há muito tempo, com o qual se restituiu o tempo do jogo do faz-de-conta (SISTO, 2005, p.32).

Mesmo que não seja um contador de excelência 'alguns recursos fará dele, se não o artista de dotes excepcionais, um mestre capaz de transmitir com segurança e entusiasmo um texto para os pequenos' (DINORAH, 1995 p.50).

Durante o tempo de atuação pude aplizar alguns recursos criativos para contação de histórias uns recriando a minha maneira a partir de outras ideias e outros criados pela 
autora proporcionando novos recursos e possibilidades.

Fazendo uso de recursos criativos na Biblioteca Escolar dinamiza a hora do conto e as atividades criando uma atmosfera de intimidade entre $\mathrm{o}$ bibliotecário e o participante, aproximando o mesmo para novas possibilidades no instante da contação, aproveitamos para compartilhar e estimular a sua criação individual, que elas possam ser úteis na sua próxima contação ou mesmo numa atividade na escola. São eles:

\section{Histórias enlatadas}

O objetivo da utilização da história na lata além utilizarmos um recurso reciclável criarmos um mistério com relação a história provocando curiosidade e imaginação em relação a história que serár contada ou ainda pode decorar com o tema da história. Dependendo do público e da proposta a ser aplicada e conforme o grupo que participará da contação, deixe sua imaginação fluir, utilize latas variadas caso realize mais de uma contação de acordo com o tempo estimado da contação. Pode se ainda convidar o aluno a realizar a contação estimulando assim sua participação. Lembrando que estará contribuindo com o meio ambiente reutilizando o metal.

\section{Cabide de histórias}

Utilizamos cabide de roupas onde a história pode contada com uma narrativa visual (cada cabide uma imagem sequenciando a história) o mesmo formato serve ainda para expor a história criada (dentro de saquinhos plásticos) ou até mesmo para promover alguns livros no espaço da biblioteca.

\section{chuva \\ Contação de histórias com guarda}

Um guarda chuva que também guarda histórias esse recurso deve está pronto conforme a história que será contada, a sua imaginação pode dá asas a uma contação diferenciada e divertida.

Historia com rolinhos de papel higiênico

Esse recurso também pode ser utilizado para contação, estimulando o imaginário e o trabalho cooperativo com a escola (parceria com professor de artes,ciências etc) onde pode se abordar o tema ambiental e de sustentabilidade. Com o objetivo de estimular e orientar sobre a importância e cuidados com a natureza. Depois de pronto apresentar a história apresentando ou expondo os trabalhos de cada participante.

\section{Histórias com Brinquedos de papel}

Os brinquedos de papel sempre fizeram parte do nosso universo quando criança e como bibliotecária atuando com o público escolar, resgatamos essa brincadeira-atividade e com o resultado utilizamos como recurso para contar história depois do brinquedo está finalizado.

O objetivo da utilização desse recurso é resgatar o brinquedo de papel e apresenta-los para aqueles que não conhecem. Os brinquedos de papel também são opções que enriquecem uma contação, podem ser levados pronto ou pode se incluir os participantes a realizarem a construção dos brinquedos sob a supervisão da professora e colaboração da bibliotecária escolar, tudo dependerá do tempo estimado para a dinâmica a ser aplicada podendo ainda previamente antecipar as etapas em virtude do tempo e depois de pronto fazer uso do que foi construído e apresentar a história.

Podemos incluir os participantes a realizarem a construção dos brinquedos (personagens) com orientação da professora e colaboração da bibliotecária.

Caso o tempo estimado da contação envolva outras atividades, pode se ainda antecipar as etapas e em seguida fazer uso do brinquedo construído utilizando como recurso para apresentar a história. Há vários sítios que disponibilizam gratuitamente e o custo dependerá da quantidade de alunos. Também pode ser entregues como lembrancinha ao final da história.

\section{Envelopes multicores}

Em envelopes coloridos coloque fragmentos de histórias e espalhe sob a mesa que servirá de apoio e permitirá a visualização dos envelopes além de estimular a curiosidade em relação ao conteúdo, o objetivo de utilização desse recurso é promover a leitura de forma espontânea a partir do envelope colorido e dá inicio a história que será contada. O mesmo recurso pode ser ampliado caso haja uma atividade de escrita criativa para resultar em produções textuais fantásticas. Ouse. Crie. Recrie.

História confeccionada com papel de presente 
Quando criamos essa possibilidade não imaginávamos a dimensão e resultados de produção textual enriquecedores. O objetivo é reutilizar o papel de presente que por vezes é jogado fora, estimular a criação de uma história, apresentar a importância da ilustração, estimular várias outras possibilidades. O papel de presente ilustrado pode ser usado na criação uma narrativa visual (livro de imagem, sequencia da história etc) e também uma produção textual, essa escolha ficará a critério do dinamizador.

\section{Pizza poética}

As poesias são escolhidas são escritas nas fatias de pizza feitas com EVA, colocadas numa caixa de pizza e o objetivo é matar sua fome de leitura, utilizamos em atividades na biblioteca com público escolar, bem como no projeto Amor Literário em ação alusiva ao dia dos namorados em convite recebido para participar da Ação Cultural, intiltulada Fundamentos políticos da ação cultural em bibliotecas na qualidade de mediador dentro da disciplina de Ações culturais do Curso de Biblioteconomia da UFPB, fizemos uso do recurso para envolver os alunos no ambiente e na temática da palestra.

\section{CONSIDERAÇÕES FINAIS}

A contação de histórias como um elemento a mais para o ensinoaprendizagem, suscita $\mathrm{o}$ interesse dos indivíduos pelo conhecimento, o que se acredita ser um dos caminhos para melhorar a qualidade da educação escolar.

No presente trabalho buscamos apresentar alguns recursos criativos para auxiliar na contação de história, nós bibliotecários sabemos que a formação de novos leitores não é algo que possa ocorrer de forma imediata, mais podemos contribuir de forma divertida para alcançarmos indivíduos para o universo da
Biblioteca e consequentemente da leitura. E preciso conhecer, testar novas metodologias e aplica-las com dinamismo apoiando no ensino e na aprendizagem dos educandos.

Portanto, conclui-se que a valorização da contação de histórias na Biblioteca escolar contribui para um desenvolvimento da aprendizagem ampliando e estimulando o aumento do gosto pela leitura e os recursos auxiliares e criativos utilizados na contação de história mostrou-se uma saída para colaborar com a promoção, estímulo e atração para Biblioteca Escolar, utilizando-se de elementos inseridos no contexto escolar, onde aplicados e explorados, proporcionará um ensinamento siginificativo através do encantamento das palavras.

\section{REFERÊNCIAS}

\section{BUSATTO, Cléo. A Arte de Contar}

Histórias no século XXI. Rio de Janeiro: Vozes, 2006.

DINORAH, M. O livro infantil e a formação do leitor. Petrópolis: Vozes, 1995.

FREIRE, Paulo. A importância do ato de ler. São Paulo: Cortez, 1992.

\section{REVISTA NOVA ESCOLA. Ler é diferente} de contar. Disponível em: $<$ http://acervo.novaescola.org.br/creche-preescola/ler-diferente-contar-historias683010.shtml>. Acesso em: 15.08.2016.

SISTO, Celso. Textos e pretextos sobre a arte de contar histórias. 2ed. Curitiba:positivo, 2005. (Série: Práticas educativas). 